\title{
PRODUCTION OF EDIBLE SUGARS FROM BIOMASS USING PILOT - SCALE UNIT
}

\author{
Mostafa N. A. ${ }^{\text {a* }}$ and Abd ELmoez M.H. ${ }^{\text {a }}$ \\ ${ }^{a}$ Department of Chemical Engineering, Faculty of Engineering, Minia University, Egypt \\ * Corresponding author: Prof. Dr. Nagat Abdalla Mostafa \\ Dr_eng_hanem@yahoo.com
}

\begin{abstract}
:
The production of bio-based chemicals and fuel from biomass is considered cleaner production technology for environmental protection. In the present study, establishing a new process to convert biomass to highly pure sugars and solid biofuel by concentrated acid hydrolysis was investigated. The sugar production process was based on two-steps concentrated $\mathrm{H}_{2} \mathrm{SO}_{4}$ hydrolysis of rice straw followed by separation and purification of sugars. Moreover, ethanol was separated from acids by using a distillation unit. The hydrolyzer unit can convert $10 \mathrm{~kg} / \mathrm{h}$ rice straw to sugars, and their final yield was $1 \mathrm{~kg}$ sugars per batch. An economic method for separation of sugars by precipitation using ethanol and highly efficient acid recovery (90\%) and ethanol (95-98\%) was achieved without using resins. High-performance liquid chromatography analysis for hydrolysate revealed that it contains $77 \%$ xylose, which can be used as natural diet sugars. The production of $70-100 \mathrm{~kg}$ natural diet sugars and $700 \mathrm{~kg}$ solid biofuel (Calorific value of $6952 \mathrm{~kJ} / \mathrm{kg}$ ) were obtained from $1000 \mathrm{~kg}$ rice straw. The results from the pilot plant could be considered as a step towards the commercialization of the process.
\end{abstract}

Keywords: Biomass, edible sugars, solid biofuel, pilot-scale unit

\section{INTRODUCTION}

There are various biomass sources such as wood and wood wastes, crops, waste by-products, municipal solid wastes, animal wastes, waste from food processing, and aquatic plants and algae [1]. Because of the energy crisis, lignocellulosic biomass has emerged as a potential substitute for maintaining environmental sustainability. However, the conversion of biomass into valueadded products still faces challenges in finding a proper unit operation. The cost-intensive of enzymatic system limits effective saccharification to hydrolyze the biomass and considered the stiffnecked of the process [2].

Green production technology for the alternative chemical and energy resource based on biomass has attracted increasing interest. However, their commercialization will require several technologies, such as low-cost feedstock. In Egypt, the agricultural residues are estimated to be over 35 million tons/year, and their disposal causes an environmental problem. For instance, rice straw causes black clouds. Plant-based materials containing cellulose are feedstocks that may be susceptible to acid or enzymatic hydrolysis [3]. There are several technologies available for the conversion of lignocellulosic. The main difference between these technologies is different catalysts used for the brake-down of polysaccharides in the raw material [4].

Fractionation of lignocellulosic materials by organosolv pretreatment is concerned in many types of research. The valorization of hemicellulose- and lignin-rich fractions for highvalue applications are the main achievements of Received:20 December, 2020, Accepted:1 March 2021 these researches. Organosolv-based processes are considered economically attractive due to their high solid pretreatment loadings and little water usage [5]. The fractionation of lignocellulosic material can be taking place by several convenient techniques. However, the use of strong acids and bases, high temperature and pressure requirements, and expensive instrumentation make the pretreatment methods challenging to use. Therefore, pretreatment techniques using greener solvents such as supercritical fluid, ionic liquid, and deep eutectic solvent (DES) can overcome these difficulties. But to apply the greener technologies commercially, many pilot-scale scales and more studies are mandatory [6].

Fractional hydrolysis is a novel process that used different inorganic acids to fully recover the number of fermentable sugars as separate fractions, direct from the biomass with minimum toxics generation for bioethanol production [7,8]. Supercritical water ultrafast hydrolysis of the cellulosic fraction can be considered as the core of this process. The operation is a continuous system that should be a real alternative to removing lignocellulosic fractionation [9].

The vital step for the production of sugars and biobased chemicals is the hydrolysis of lignocellulosic biomass. To measure the time-dependent formation of sugars (glucose, xylose, mannose), and furfurals, a semi-continuous plant with diluted sulphuric acid as a catalyst at different hydrolysis temperatures for three types of lignocellulose (hardwood, softwood, and grass) were studied [10].

Sugars' recovery from agricultural biomass by the FASTSUGARS process was investigated on a pilot plant scale. It was found that the hydrolysis of 
biomass was slow down by controlling particle size because large particle size acted as a mass transfer resistance. This slow hydrolysis resulted in lower conversion and reduced sugars' degradation yield by $15 \%$ lower in the pilot plant. Besides, higher selectivity to sugars was obtained [11].

The xylooligosaccharides (XOS) and fermentable sugars production from Miscanthus using steam explosion (S.E.) pretreatment was studied on a pilot plant scale. Enzymatic hydrolysis for both the XOS-rich hydrolysate and solid residues was applied to obtain fermentable sugars [12]. In the pilot-scale unit, oil palm as a renewable resource for bioethanol production was investigating [13], and modularizing bioethanol production from lignocellulose data was collected [14].

Crystalline cellulose and natural hemicellulose become utterly soluble in $72 \% \mathrm{H}_{2} \mathrm{SO}_{4}$ or $42 \% \mathrm{HCL}$ at room temperature. Since the polysaccharides' depolymerization favors the formation of oligosaccharides, nearly no monosaccharides are decomposed in concentrated acid. It is essential to appreciate that the cellulose chains dissolve in concentrated acid and then hydrolyze in a homogeneous reaction medium to oligomers [15]. The method of using concentrated sulfuric acid for biomass hydrolysis has many advantages. For instance, this method can be proceeded at low reaction temperature and little by-product, in addition to high yield. However, this method has the disadvantage of the high cost for acid recovery. Many researchers investigated an electrodialysis method to recover sulfuric acid from the concentrated acid hydrolysate of plant cellulose material, but this method is high in running and capital intensive [16]. Afterward, new systems of recovering acid using strong acid cation exchange resins to adsorb sugars in the liquid portion were studied. However, this new system still has a disadvantage of the high recovery cost due to resins' low adsorption capacity [17].

A method for producing carbohydrates from plant cellulose material by concentrated sulfuric acid was studied [18]. The process was stopped at the middle before diluting the acid to a concentration between $20 \%$ and $30 \%$. It was then mixing the concentrated acid main hydrolysate of plant cellulose material with a liquid organic precipitant, thus obtaining a sugar precipitate and an organic precipitant solution containing sulfuric acid. This method has many problems, such as low sugars yield, and the final product will be oligosaccharides, but not glucose.

A complete process for producing highly pure edible sugars and solid biofuel from rice straw was investigated on a pilot-scale in the present study. The concentrated acid hydrolysis was briefly achieved by using $70 \%$ acid concentration then diluted to $25 \%$ or $30 \%$. Then, evaporating the optimum amount of water from hydrolysate to enable the sugars to precipitate. Besides, we use precipitant to decrease the solubility of sugars. At the end of the process, the precipitant is separated from acid by evaporation and condensation and reused. The study's purpose was to establish a new technique to determine the potential amount of sugar and solid biofuel production from $1000 \mathrm{~kg}$ rice straw; based on the pilot-plant operation. Furthermore, the amount of acid and ethanol recovered from the batch process were calculated.

\section{MATERIAL AND METHODS}

\subsection{Materials}

The raw materials used were Rice straw; they were sun-dried and reduced in particle size to be suitable for handling. The chemicals used are $98 \%$ sulfuric acid of industrial grade and $95 \%$ ethanol and lime, purchased from El-Gomhouria Pharmaceuticals and Chemicals Company, Cairo, Egypt.

\subsection{Equipment}

Hydrolyzing tank (iron tank lined by polyvinylidene difluoride (PVDF)); fire source; stainless steel screener (with cheesecloth made from polyester); plastic clarifier; separator for acid and alcohol (batch distiller with a $5 \mathrm{~K}$.W. heater) and spray dryer.

\subsection{Procedure}

\subsubsection{Hydrolysis reaction}

A $70 \%$ sulfuric acid solution was prepared and mixed with rice straw (solid: liquid ratio, 1: 1) with manual intermittent agitation (for the 15-minute interval) and at $60-70^{\circ} \mathrm{C}$ for $20 \mathrm{~min}$., followed by water addition to reaching the acid concentration to $25 \%$ and heating at $100{ }^{\circ} \mathrm{C}$ for $1 \mathrm{~h}$.

\subsubsection{Separation process}

After the hydrolyzation process, the solid fraction, mainly lignin, was separated from the hydrolysate using a cheesecloth screener. Then the hydrolysate transfer to a clarifier to settle the particles down. Experimental work was done to compare filtration and sedimentation, and it was found that sedimentation was more effective, easy, and cheaper. Also, the long residence time during filtration may increase the solubility of sugars in ethanol and lead to high losses of sugars in the ethanol stream, therefore, decrease the final yield of sugars.

\subsubsection{Concentration and separation of sugar from hydrolysate}

The Concentration of hydrolysate was taken place by evaporation of $10,20,30,35,38,44 \%$ volume/volume hydrolysate to determine the optimum percent removal of the solution before the sugars being burned. The addition of ethanol to the solution was 2-3 times the hydrolysate volume. Then, separation of the liquid phase (acid and alcohol) from the sugars followed by washing the sugars with ethanol, and the remaining amount of ethanol was evaporated. The sugar solution was neutralized by lime and using a spray dryer to 
separate sugars. Finally, a liquid phase that contains acid and alcohol was evaporated to separate and recover both alcohol and acid from being reused in the process.

\subsubsection{Preparation of silica from solid residues}

From rice straw and cotton gin trash, which contain high amounts of silica, silicic acid was extracted from the solid residues using 5\%-10\% sodium hydroxide. Concisely, the solids were heated, pressed, and washed with water to remove a liquid. Reduce the liquid's $\mathrm{pH}$ by treating with acid, thus, creating a separated residue, preferably by filtration. Pure silica can be obtained by bleaching and can be further treated to produce sodium silicate, potassium silicate, or other useful materials.

\subsection{Analysis}

The sugar concentration was determined as total reducing sugars by the phenol-sulfuric acid method [19], by Fehling analysis method [20], and the hydrolysate sugars composition by HighPerformance Liquid Chromatography (HewlettPackard Liquid Chromatograph Series 1050 with R.I. detector using Bio-Rad Aminex HPX-87C column $300 \mathrm{~mm} \times 7.8 \mathrm{~mm}$ and deionized water as mobile phase, injection volume of $15 \mu \mathrm{l}$ at $70^{\circ} \mathrm{C}$ with a flow rate of $0.6 \mathrm{ml} / \mathrm{min}$ ) at Central - Labs, Egyptian Petroleum Refinery Institute. The Gross calorific value (K.J./kg) of three samples of the solid residues, main lignin from three different experimental runs, was determined according to ASTMD 240 using Tarr 200 calorific value tester at Central - Labs, Egyptian Petroleum Refinery Institute. The silica was determined by NICOMP 380 ZLS dynamic light scattering instrument (PSS, Santa Barbara, CA, USA) at Nanomaterial Investigation Lab., Central Laboratory Network, National Research Center, Cairo.

\section{RESULTS AND DISCUSSION}

\subsection{Concentration and separation of sugar from} hydrolysate

The hydrolysate was concentrated by solvent evaporation. The optimum removal of solvent was $38 \%$ volume without burning sugar, which increased sugar concentration in hydrolysate from 16.46 to $27 \%$. Also, sugar should be washed with ethanol after separation to be free from furfural. Thus, sugar powder became very pure after two washing times, as shown in Figure 1.

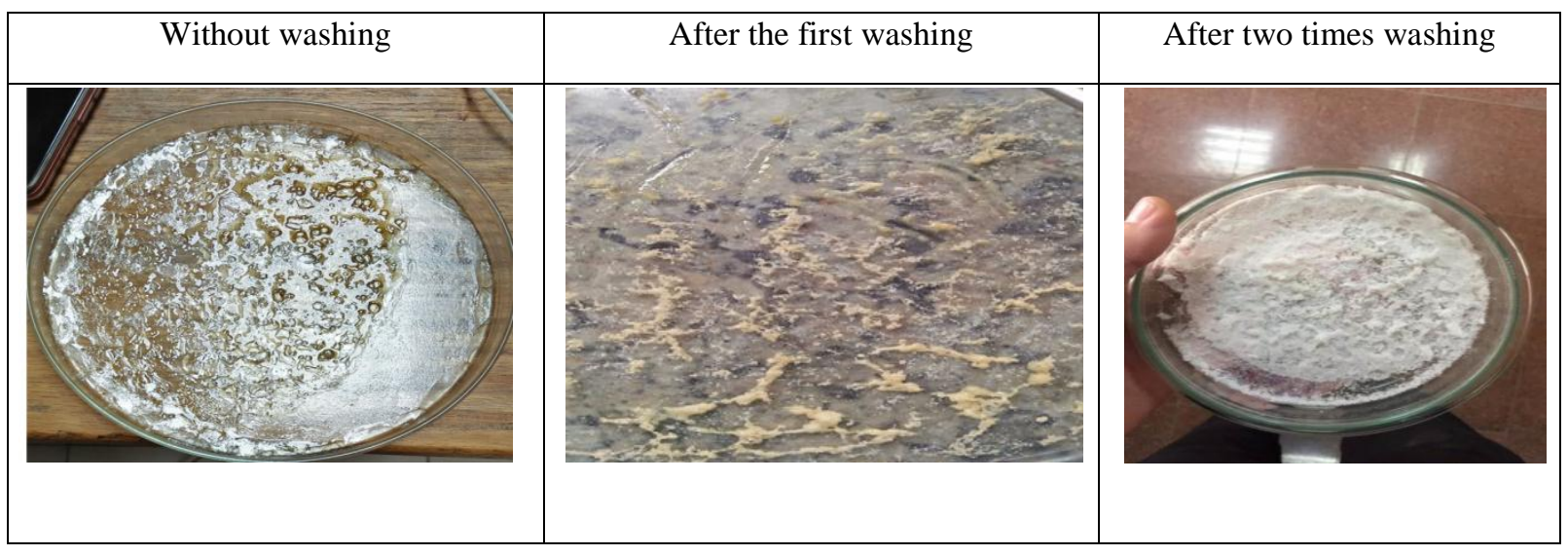

Fig. 1. Effect of washing sugar powder with ethanol

\subsection{Quantitative analysis of sugar}

Table 1 has represented the results of the quantitative analysis of sugars. Our new method resulted in about $38 \%$ sugar production from the hydrolysate. This amount of sugar is the highest $\%$ sugar obtained so far. For instance, previous studies such as Farone et al., and Wijaya et al., produced about $15 \%$ sugar and less than $10 \%$ sugar, respectively [21-22]. Also, it was found that the hydrolysate has higher sugar content compared with the final sugar powder. This can be explained

Table 1. Quantitative analysis of sugar in hydrolysate and sugar powder

\begin{tabular}{|l|l|}
\hline The analysis method & $\%$ of sugar / biomass \\
\hline Phenol - sulfuric acid & $38 \%$ (g sugar / \\
& $100 \mathrm{ml}$ hydrolysate)
\end{tabular}

by the fact that there are losses during separation and washing with ethanol. Therefore. Integration of the processes is recommended to reuse ethanol from the washing step for sugar separation in the next batch. The composition analysis of sugars in hydrolysate by HPLC is presented in Table 2. As shown in Table 2, the hydrolysate contains a higher composition of xylose (77\%) compared with glucose $(11.3 \%)$ and arabinose $(11.7 \%)$. Therefore, the produced sugar can be used as natural diet sugar.

$\begin{array}{ll}\text { Fehling } & 25 \% \text { (g sugar / } \\ & 100 \mathrm{ml} \text { hydrolysate) } \\ \text { Sugar powdered } & 7-10 \% \text { (g sugar / } \\ & 100 \mathrm{~g} \text { rice straw) }\end{array}$


Table 2. The composition analysis of sugars in hydrolysate by HPLC

\begin{tabular}{|l|l|}
\hline Sugar type & Percent \\
\hline Xylose & 77 \\
Glucose & 11.3 \\
Arabinose & 11.7 \\
\hline
\end{tabular}

3.3. Quantitative analysis of the produced solid fraction (mainly lignin) and silica

The material balance for sugar production from rice straw was $700 \mathrm{~kg}$, mainly lignin produced from $1000 \mathrm{~kg}$ rice straw. As shown in Table 3, the solid fraction (primarily lignin) has a mean gross calorific value of $6952 \mathrm{~kJ} / \mathrm{kg}$. Therefore, this solid fraction can be used as biofuel, which increases the process's economy. Moreover, this solid fraction's calorific value is close to bagasse, which has a gross calorific value of $9500 \mathrm{~kJ} / \mathrm{kg}$ [23]. However, this solid fraction's lower calorific value may be attributed to its high moisture and ash residues.

The silica produced from the residue fraction after the hydrolysis of rice straw can be considered a valuable by-product with $99 \%$ of distribution > $1018 \mathrm{~nm}$, as shown in Figure 2. The chemicals were recovered with $90 \%$ and $95-98 \%$ for sulfuric acid and ethanol to achieve maximum economy. The losses of acid may be due to the gaseous fumes (mainly $\mathrm{SO}_{3}$ and $\mathrm{CO}_{2}$ ) that evolved during the hydrolysis process. Therefore, using an absorption unit connected to the gaseous fumes' outlet for pollution control is recommended. Also, much amount of water can be recovered from evaporation processes and reused.

Table 3. The gross calorific value of the produced solid fraction (mainly lignin) $\mathrm{kJ} / \mathrm{kg} *$

\begin{tabular}{|ll|} 
Sample ID & Results \\
\hline 1 & 6873 \\
2 & 7267 \\
3 & 6716 \\
\hline
\end{tabular}

*Test was made according to ASTMD - 240

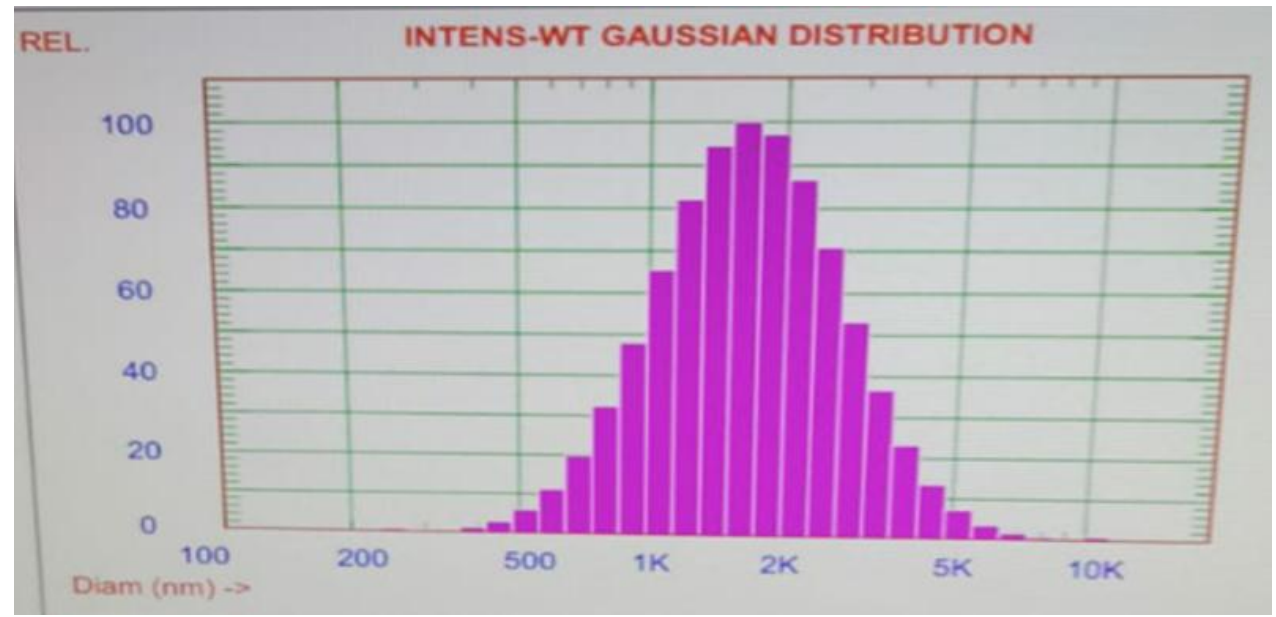

Fig. 2. Gaussian distribution analysis of silica particle

\subsection{Design part}

The previously discussed economic method was used to construct a pilot plant unit in the present study. Figure 3 shows the flow sheet for the production of edible sugars and solid fuel from rice straw. The process flow diagram for the pilot plant to produce edible sugars and solid biofuel from rice straw was depicted in Figure 4. Moreover, the quantitative flow sheet for edible sugar and biofuel from rice straw was illustrated in Figure 5. Concisely, $1000 \mathrm{~kg}$ rice straw can be converted to $100 \mathrm{~kg}$ edible sugar and $700 \mathrm{~kg}$ solid biofuel and recovered $90 \%$ and $95-98 \%$ for sulfuric acid and ethanol. 
Vol. 41, No.2. July 2022

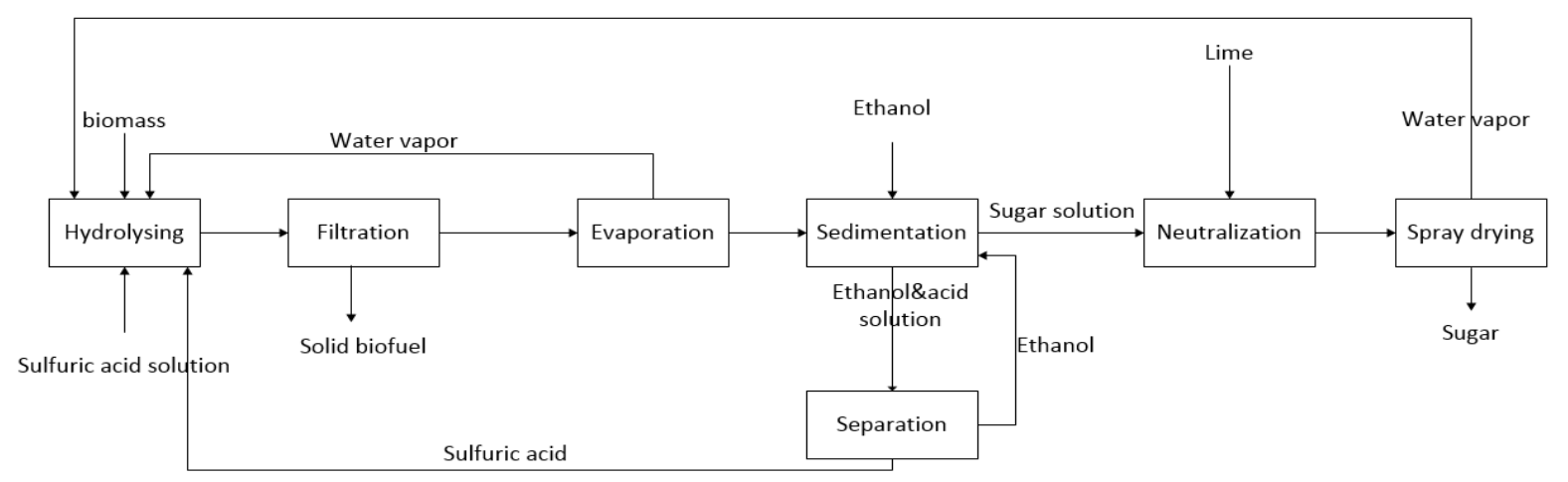

Fig. 3. Flowsheet for production of edible sugar and solid biofuel from rice straw

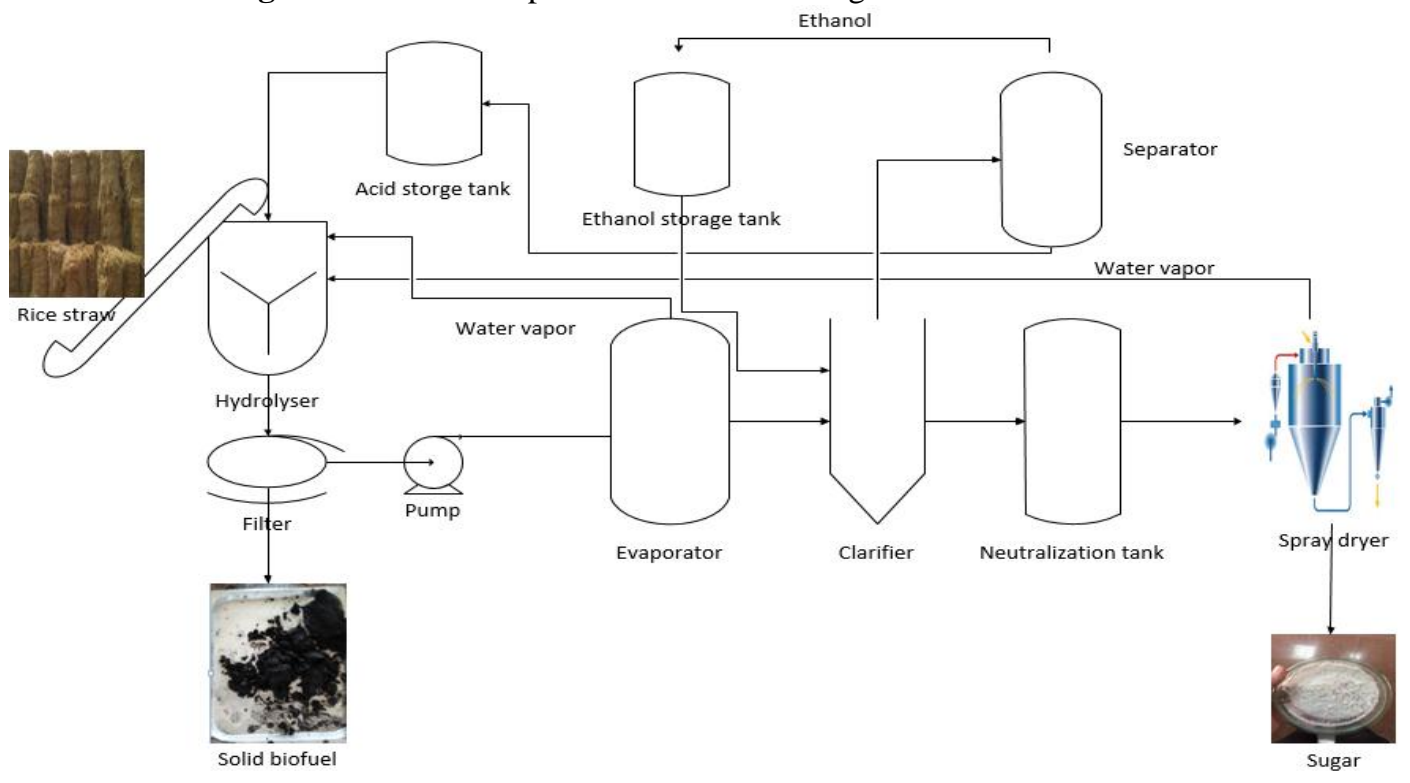

Fig. 4. Process flow sheet of the pilot plant for the production of edible sugars and solid biofuel from rice straw 
Vol. 41, No.2. July 2022

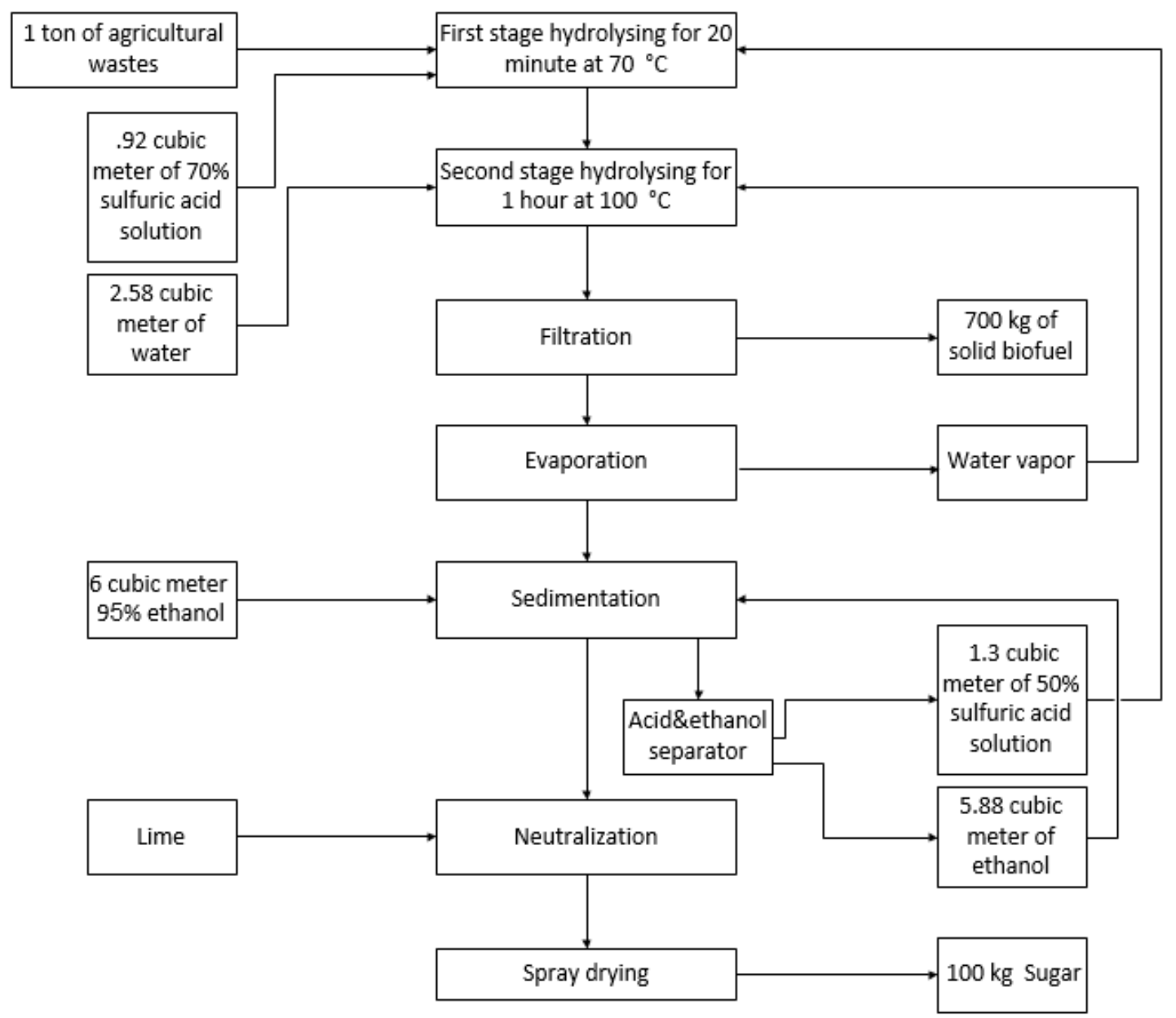

Fig. 5. Quantitative flow sheet for the production of edible sugar and biofuel from rice straw

On the other hand, there are many losses during operations. For instance, losses of acid are mainly gaseous fumes during hydrolysis, losses of the lignin during the process, some of the sugars converted to furfural compounds remained with the acid, and not all sugar precipitated. Some of the sugar remains in ethanol.

The sugar production process was based on twosteps concentrated $\mathrm{H}_{2} \mathrm{SO}_{4}$ hydrolysis of rice straw followed by separation and purification of sugars. Moreover, ethanol was separated from acids by using a distillation unit. The hydrolyzer unit can convert $10 \mathrm{~kg} / \mathrm{h}$ rice straw to sugars, and their final yield was $1 \mathrm{~kg}$ sugars per batch. Based on the recovery of $1000 \mathrm{~kg}$ rice straw to edible sugar and solid biofuel per month (working days are usually assumed 25 days per month), the constructed hydrolyzer unit can be used for four batches per day (i.e., convert $40 \mathrm{~kg} /$ day). Table 4 represents the design feature for edible sugar and solid biofuel production equipment from rice straw.

Table 4. The design features for edible sugar and solid biofuel production equipment from rice straw

\begin{tabular}{|c|c|c|c|}
\hline Item & Equipment & Design Feature & The material of Const. \\
\hline 1 & Ethanol storage tank & (Cylindrical) Volume $=200 \mathrm{~L}$ & High-Density Polyethylene \\
\hline 2 & Acid storage tank & (Cylindrical) Volume $=100 \mathrm{~L}$ & High-Density Polyethylene \\
\hline 3 & Hydrolysis tank 1 & (Cylindrical) Volume $=200 \mathrm{~L}$ & Antiacid bricks \\
\hline 4 & Hydrolysis tank 2 & (Cylindrical) Volume $=200 \mathrm{~L}$ & Iron coated by PVDF \\
\hline 5 & Separator (distiller) & $\begin{array}{l}\text { Batch system with A } 5 \text { K.W. heater } \\
\text { Volume }=200 \mathrm{~L}\end{array}$ & Iron coated by PVDF \\
\hline 6 & Water evaporator & (Cylindrical) Volume $=200 \mathrm{~L}$ & Iron coated by PVDF \\
\hline 7 & Squeezing machine & Capacity $=50 \mathrm{~L} / \mathrm{h}$ & Iron coated by PVDF \\
\hline 8 & Filtration device & Capacity $=50 \mathrm{~L} / \mathrm{h}$ & Polypropylene filter \\
\hline 9 & $\begin{array}{l}\text { Neutralization tank } \\
\text { (lime) }\end{array}$ & (Cylindrical) Volume $=200 \mathrm{~L}$ & High-Density Polyethylene \\
\hline 10 & Spray dryer & Capacity $=20 \mathrm{~L} / \mathrm{h}$ & Stainless steel or cast iron \\
\hline
\end{tabular}




\section{CONCLUSION}

An economical method to convert biomass to sugars and solid biofuel using a concentrated acid hydrolysis process was applied to construct the pilot plant scale. Similar trends were obtained by performing the rice straw's hydrolysis in the pilot plant, like sugar and solid fuel yield. The produced sugars contain $77 \%$ xylose and can be used as natural diet sugars. Also, the produced solid fuel has a high calorific value of $6952 \mathrm{~kJ} / \mathrm{kg}$. The silica extracted from solid fraction can be considered a valuable by-product with $99 \%$ distribution > 1018 $\mathrm{nm}$. Ultimately, the highly efficient recovery of acid (90\%), ethanol (95 - $98 \%$ ), and water recycling were achieved to increase the process's economy. As expected, the production of edible sugars and solid fuels from rice straw using concentrated sulfuric acid hydrolysis seems useful. Therefore, it is feasible to produce edible sugars and biofuel from lignocellulosic waste in the near future.

\section{REFERENCES}

1- Ayhan D., Biomass resource facilities and biomass conversion processing for fuels and chemicals. Energy Conversion and Management, Vol. (42), No. 11, p.1357-1378, 2001.

2- Dibyajyoti H. and Mihir k., Lignocellulosic conversion into value-added products: A review. Process Biochemistry, Vol. (89), p. 110- 133, 2020.

3- Bilal M.M. and Robert C. H., Biofuels for green aviation. In Ramesh A., Fayette C., Andrea S., Allan S., Green Aviation, 1st Edition, John Wiley \& Sons Ltd. U.K., p.186195, 2016.

4- Hwei-Ting T., Kendall R., Geoffrey B., Emerging technologies for the production of renewable liquid transport fuels from biomass sources enriched in plant cell walls, Frontiers in Plant Science, Vol. (7), p. 1854, 2016.

5- Jorge A. F., Mohammad J.T., Improving the economy of lignocellulose-based biorefineries with organosolv pretreatment, Review. Bioresource Technology, Vol. (299), p. 122695, 2020.

6- Ranen R., Md S. R., Douglas E. R., Recent Advances of Greener Pretreatment Technologies of Lignocellulose. Current Research in Green and Sustainable Chemistry, Vol. (3), p. 100035, 2020.

7- Archana M. and Sanjoy G., Bioethanol production from various lignocellulosic feedstocks by a novel "fractional hydrolysis" technique with different inorganic acids and coculture fermentation. Fuel, Vol. (236), p. 544-553, 2019.

8- Archana M. and Sanjoy G., Saccharification of kans grass biomass by a novel fractional hydrolysis method followed by co-culture fermentation for bioethanol production. Renewable Energy, Vol. (146), p. 750-759, 2020.

9- Alonso E., The role of supercritical fluids in the fractionation pretreatments of a wheat bran-based biorefinery, Review. The Journal of Supercritical Fluids, Vol. (133), p.603-614, 2018.

10- Katarzna S., Stephanie G., Andreas K., Andrea K., Jorg S., David S., Acid hydrolysis of lignocellulosic biomass: sugars and furfurals formation. Catalysts, Vol. (10), No.4, p.437, 2020.

11- Celia M. M., Tijana A., Danilo A. C., Cocero M.J., Scaling up the production of sugars from agricultural biomass by ultrafast hydrolysis in supercritical water. The Journal of Supercritical Fluids, Vol. (143), p. 242-250, 2019.

12- Rakesh B., Ana W., David N., Maurice B., John C., David L., Joe G., Pilot-scale production of xylo-oligosaccharides and fermentable sugars from Miscanthus using steam explosion pretreatment. Bioresource Technology, Vol. (296), p. 122285, 2020.

13- Yanni S., Dyah S., Eka T., Sudiyarmantoa, Kiky C., Yosi A., Haznan A. and Min H., Utilization of biomass waste empty fruit bunch fiber of palm oil for bioethanol production using pilot - scale unit. Energy Procedia, Vol. (32), p. $31-38,2013$.

14- Hyungjin J., Kyeong-Eop K., Jun-Seong J., Gyeongtaek G., Jae-Wook C., Haznan A., Byoung S., Dong-Jin S. and Gi-Wook C., Production of anhydrous ethanol using oil palm empty fruit bunch in a pilot plant. Biomass and Bioenergy, Vol. (67), p. 99-107, 2014.

15- Nosseir S. A., "Energy from Egyptian vegetable wastes", M.Sc. thesis. Alexandria University, Egypt, p. 18-19, 1987,

16- Lemaire J., Blanc C., Duval F., Théoleyre M., Pareau D., Purification of pentoses from hemicellulosic hydrolysates with sulfuric acid recovery by using electrodialysis. Separation Purification Technology, Vol. (166), p. 181186, 2016.

17- William A., John E., Method of separating acids and sugars resulting from strong acid hydrolysis, US5580389A, 1996.

18- Peihao C., Method for recovering sulfuric acid from concentrated acid hydrolysate of plant cellulose material, US8052953B2, 2011.

19- Pak S. C. and Simon M. L., A method for routine measurements of total sugar and starch content in woody plant tissues. Tree Physiology, Vol. (24), p.1129-1136, 2004.

20- Mendham J., Denney R.C., Barnes J.D., Thomas M., Vogel's Textbook of Quantitative 
Vol. 41, No.2. July 2022

Chemical Analysis, Pearson Education Ltd, England, 2000.

21- Farone W. A., John E.C., Method of producing sugars using strong acid hydrolysis of cellulosic and hemicellulosic martials, Arkenol, Inc., Las Vegas, Nev., US00556277A, 1993.

22- Wijaya Y.P., Putra RD, Widyaya VT, Ha JM, Suh DJ, Kim CS., Comparative study on twostep concentrated acid hydrolysis for the extraction of sugars from lignocellulosic biomass. Bioresource Technology, Vol. (164), p. 221-31, 2014.

23- Amornrat K., Wasan Y., Sumrerng J., Effects of moisture content in simulated bagasse by equilibrium analysis. The 4th TSME International Conference on Mechanical Engineering, Pattaya, Chonburi. 16-18 October 2013. 


\section{انتاج سكريات صالحة للأكل من الكتلة الحية باستخدام وحدة نصف صناعي}

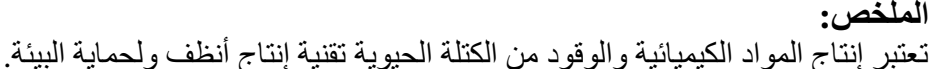

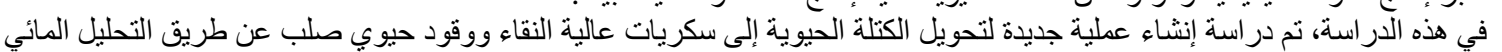

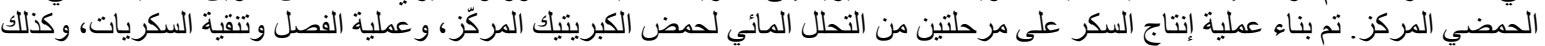

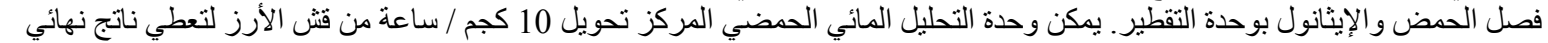

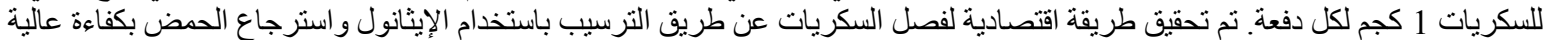

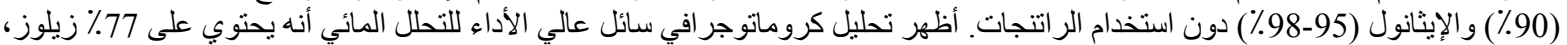

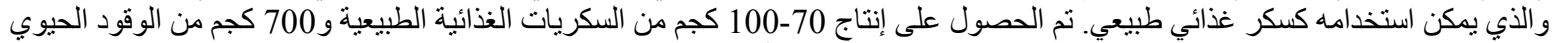

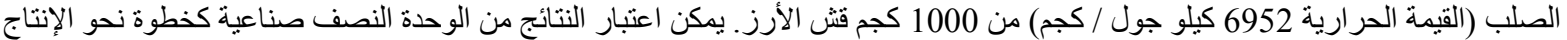
على نطاق صناعي وتجاري. 